\title{
Notes on the vocalizations of Ringed Warbling-finch (Poospiza torquata)
}

\section{Peter Boesman}

In the following we briefly analyze and compare voice of the two races of Ringed Warblingfinch (Poospiza torquata). We also try to quantify the extent of any vocal differences using the criteria proposed by Tobias et al. (2010), as a support for taxonomic review. We have made use of sound recordings available on-line from Xeno Canto (XC).

A comparison of song, illustrated with sonograms:

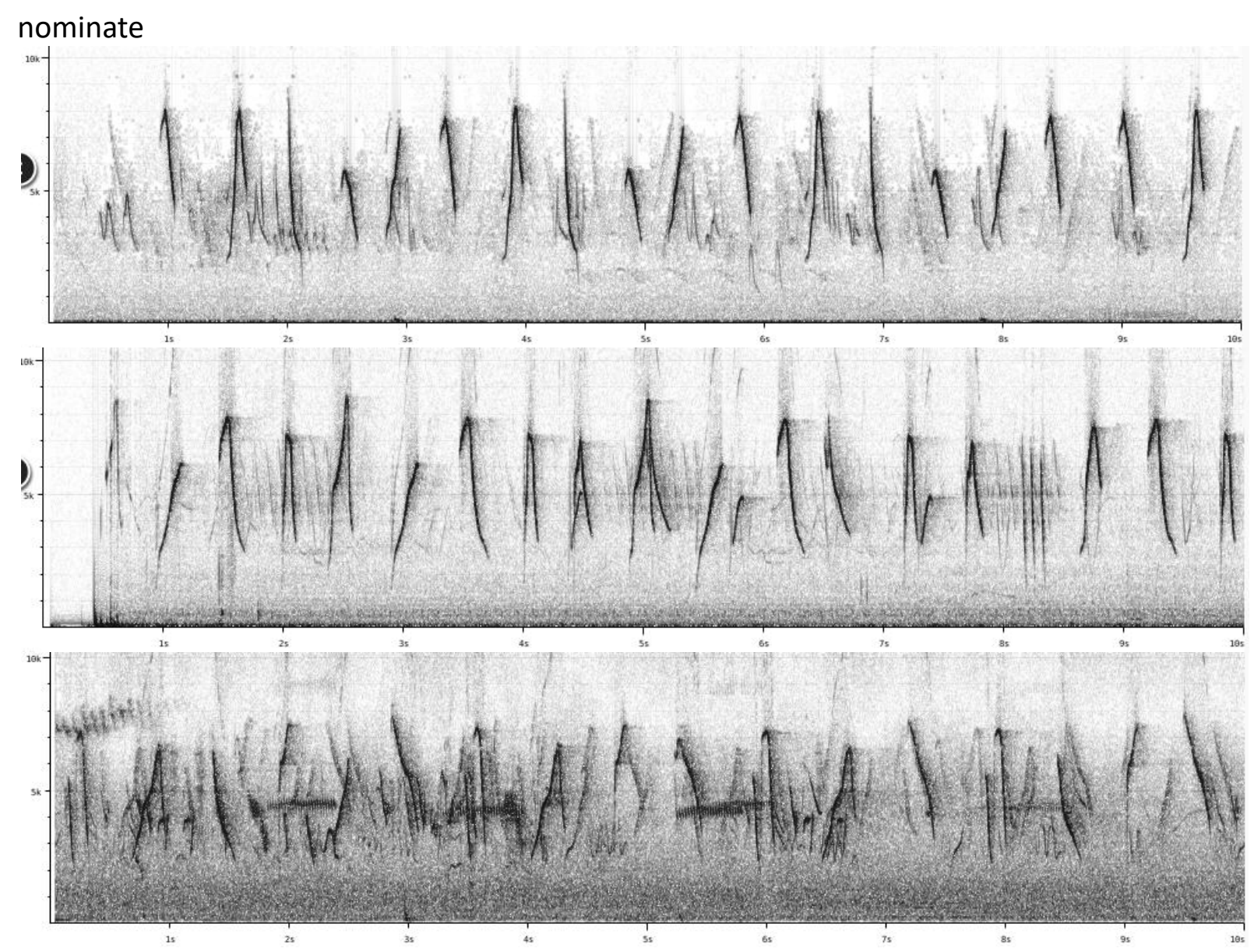

XC4704 (presumably this subspecies, but of extreme S Bolivia in austral summer)

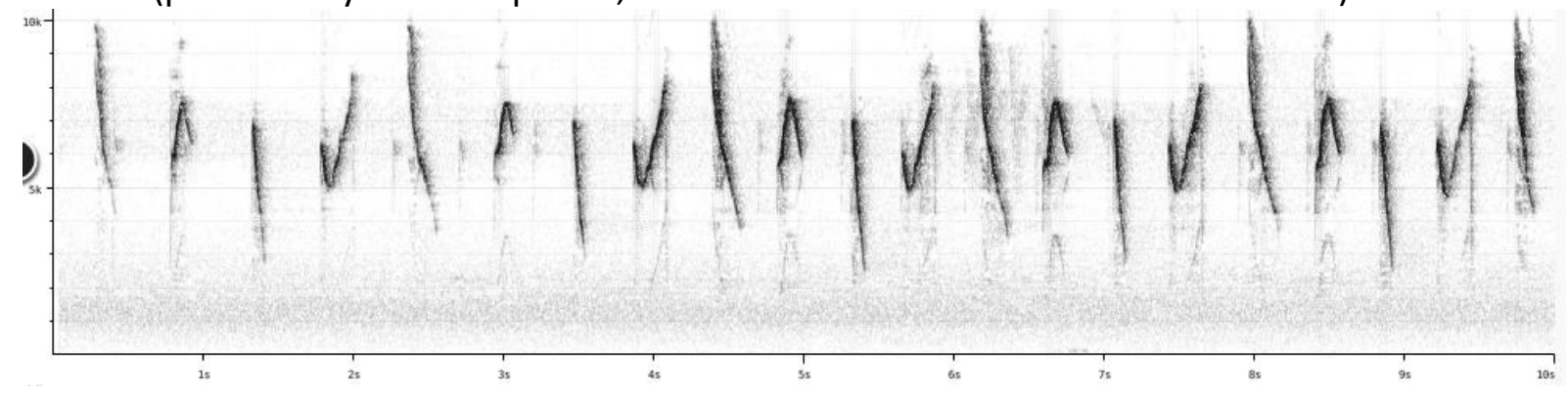



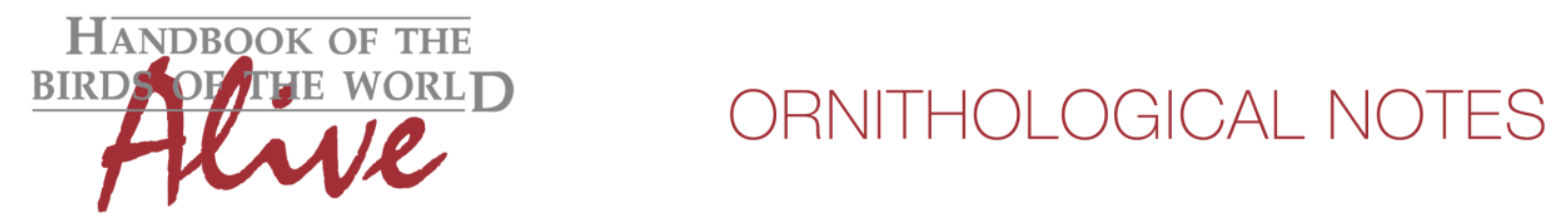

pectoralis

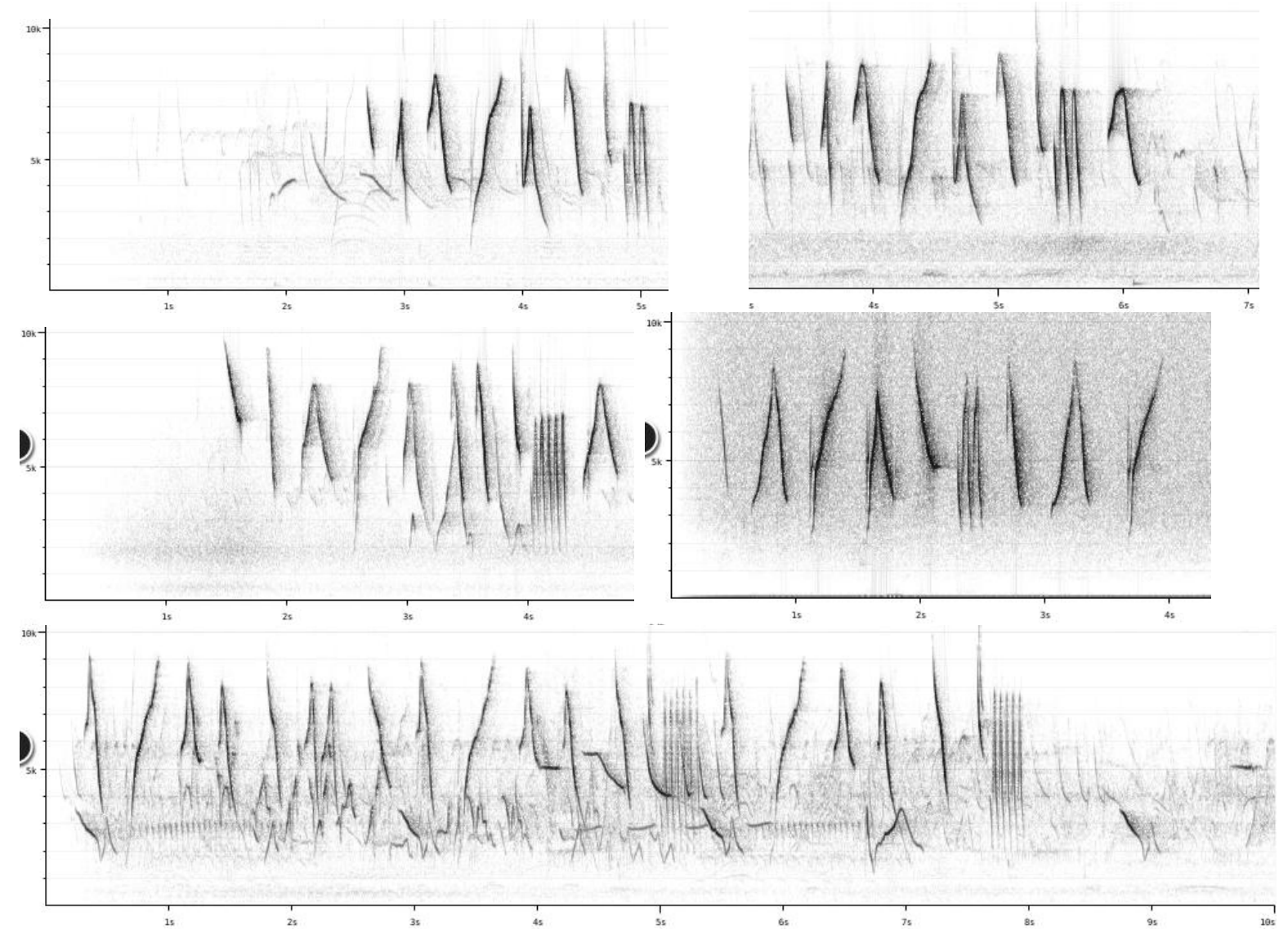

nominate $(n=4)$ has a song consisting of a repeated subphrase, which typically has 4-6 well separated notes (1.8 -2.2 notes/s). This song typically lasts for long periods (1 minute or more).

pectoralis has a song consisting of a short phrase of some 7-10 notes (2.2 - 3.0 notes/s, trills counted as 1 ) without any repetition, and typically having a single trilled note in the phrase. Song phrase duration c. 3-4s. Only rarely a longer song is given (max. $8 \mathrm{~s}$ ), in which a subphrase of 6-8 notes is repeated a couple of times.

Frequencies and note shapes of both races very similar.

There is thus a striking difference in song length, with nominate having a very long string of repeated subphrases, while pectoralis typically has a short single song phrase (song duration, score 3), occasionally doubled or tripled. pectoralis also has a faster pace of delivery (2) and always has at least a trilled note in its song phrases.

Application of Tobias criteria would lead to a total vocal score of about 5.

Some caution is needed however, given there are only 4 recordings of nominate, and a recording from $\mathrm{S}$ Bolivia is of unknown racial identity. More recordings of nominate are needed to confirm these findings. 
This note was finalized on 4th July 2016, using sound recordings available on-line at that moment. We would like to thank in particular the sound recordists who placed their song recordings for this species on XC: Nick Athanas, Peter Boesman, Miguel Castelino, Niels Krabbe, Dan Lane, Bernabe Lopez-Lanus, Aidan Maccormick, Sjoerd Mayer, Paul Smith and Joseph Tobias.

\section{References}

Tobias, J.A., Seddon, N., Spottiswoode, C.N., Pilgrim, J.D., Fishpool, L.D.C. \& Collar, N.J. (2010). Quantitative criteria for species delimitation. Ibis 152(4): 724-746.

\section{Recommended citation}

Boesman, P. (2016). Notes on the vocalizations of Ringed Warbling-finch (Poospiza torquata). HBW Alive Ornithological Note 399. In: Handbook of the Birds of the World Alive. Lynx Edicions, Barcelona. (retrieved from http://www.hbw.com/node/1253793 on 2 December 2016). 